\title{
How Does Actual Reality Imitate Literary Pure Possibilities?
}

\section{Gilead A*}

Department of Philosophy, University of Haifa, Israel

*Correspondig author: Amihud Gilead, Department of Philosophy, University of Haifa, Haifa, Israel, Tel: 04-8245386; Email: agilead@research.haifa.ac.il

\section{Research article}

Volume 1 Issue 2

Received Date: September 11, 2018

Published Date: October 16, 2018

DOI: $10.23880 /$ phij-16000108

\section{Abstract}

In Oscar Wilde's The Decay of Lying, Vivian posits quite an intriguing idea: contrary to the accepted view, which has prevailed since Plato, it is not art that imitates reality but it is reality that imitates art. Fascinated by this idea, I suggest a revision of it, especially relating to the literary art. Reality actualizes, imitates, or represents individual pure, non-actual possibilities that are mind-independent (which renders the notion of possible worlds dispensable or redundant). The artistic mind reveals these possibilities by non-empirical means-intellect and imagination. On the grounds of these possibilities, we can see, recognize, identify, understand, and evaluate actualities that empirically actualize some of these possibilities. These pure possibilities are also the source of the meanings, significance, and values of the relevant actualities. Values thus pertain to the modal realm of individual pure possibilities, to which "the ought" and "the should" pertain. While Wilde's Vivian endorses a kind of idealism, I, following a special kind of realism about individual pure possibilities and about actualities as well, attempt to explain his intriguing claim on quite different grounds. Daily life may actualize or imitate, for example, some pure possibilities that masterpieces by Franz Kafka or Harold Pinter reveal. I end by challenging Erich Auerbach's view concerning the representation of reality in Western literature.

Keywords: Individual pure possibilities; Possible worlds; Realism; Idealism; Actualization; Imitation; Representation; Evaluation; Values; Fictions; Plato; Platonic philosophy of mathematics; Aristotle; Dante; Oscar Wilde; Franz Kafka; Harold Pinter; Marcel Proust; Virginia Woolf; James Joyce; Erich Auerbach.

\section{Introduction}

In a brilliant dialogue between Cyril and Vivian-The Decay of Lying by Oscar Wilde-a most surprising idea is introduced, examined, and challenged: "Nature, no less than Life, is an imitation of Art"1. Since the time of Plato, a contrary time-honored idea had prevailed: it is art that imitates life or nature, not vice versa ${ }^{2}$. This realistic approach appears to be reasonable, and, yet, Wilde has suggested quite a different idea to enlighten us.
Having claimed that realism in art is a "complete failure" (Wilde, "The Decay of Lying," p. 23), Vivian exchanges "imitation" with "representation." For instance, referring to the European arts, he mentions the "struggle between Orientalism, with its frank rejection of imitation, its love of artistic convention, its dislike of the actual representation of any object in Nature, and our own imitative spirit" (ibid.) ${ }^{3}$. In what follows, I will also use "imitation" and "representation" interchangeably.

Vivian's anti-realistic introduction links the idea that life or nature imitates art with evaluation, in the following 


\section{Philosophy International Journal}

words: "My own experience is that the more we study Art, the less we care for Nature. What Art really reveals to us is Nature's lack of design, her curious crudities, her extraordinary monotony, her absolutely unfinished condition. Nature has good intentions, of course, but, as Aristotle once said, she cannot carry them out" (Wilde, “The Decay of Lying," p. 41).

The reference to Aristotle's Poetics ${ }^{4}$ is vital to our discussion here. Unlike the historian, the poet does not relate to what has happened, but to what may happen, to what is possible according to the law of probability or necessity. Therefore, according to Aristotle, poetry is a more philosophical and higher achievement than history, for philosophy tends to express the universal-necessary, whereas history-the particular-contingent. According to Aristotle, the universal has to do with the necessary, with what should or ought to be the case, even though nature in fact fails sometimes, in particular cases, to achieve that.

To return to Vivian's idea, the genuine artist does not represent or describe what actually happened in life or in nature, which is contingent and imperfect. Unlike the historian who describes what happens in fact, the artist portrays what is possible and necessary-what could happened, meaningfully, significantly, and valuably, with a sort of necessity (on which I will elaborate below). The artist portrays what should be or ought to happen. Such a special combination of possibility, necessity, and valueof modality and axiology-is important for my understanding of the view that Wilde's Vivian expresses in "The Decay of Lying." Yet, this interpretation distances Vivian from Aristotle's view, especially from the combination of the necessary and the universal.

Vivian claims that what nature or life fails to carry out, art fulfils. Values, especially beauty, are what nature or life should carry out. Against these values, life and nature are measured and judged. We evaluate our life and nature as well according to these values. As for representation, Vivian claims: "Even those who hold that Art is representative of time and place and people cannot help admitting that the more imitative an art is, the less it represents to us the spirit of its age" ("The Decay of Lying," p.43). Thus, furthermore, art does not adequately represent or imitate nature or life. Yet, art strongly refers to, deeply touches, life and nature. What art captures is the spirit of its age.

How can we make philosophical sense of these very unusual, though brilliant, ideas, studying the relations between life, nature, and art in light of the terms representation, imitation, and evaluation? What I try to do in this paper is to make use of a metaphysical platform on which such ideas make sense and become soundly clarified. ${ }^{5}$

Even though this platform is a novel one, it is under some old Pythagorean and Platonic influence and somewhat relates to the way in which mathematical Platonists in the twentieth and twenty-first centuries have considered the relationship between actual reality and purely mathematical objects or entities, to begin with numbers. Notwithstanding, the platform is clearly modal, for it rests upon the ontology of individual pure or nonactual (and yet actualizable) possibilities, which is very far indeed from Pythagorean and Platonic way of thinking. Note that "ought" or "should" is a modal term as much as "possibility," "necessity," and "existence" are. Values and evaluation thus rest upon modality and modality pertains or relates to them, no less than they pertain to morality and ethics.

Obviously, in this paper, I proceed far from Oscar Wilde and the intriguing ideas expressed in "The Decay of Lying." Yet while providing a metaphysical modal platform for some of these ideas, I attempt to remain loyal to their spirit in my own, different way.

\section{Pure Mathematics, Aesthetical Values, and Physical Actualities}

Any entity or object that is mathematically possible is a mathematical existent, which is subject to proof. The proof demonstrates that the possible existent under discussion is also necessary. Necessity is a kind of possibility, for everything that is necessary has to be possible first. Possibility is an antecedent or fundamental condition for the existence of anything, contingent or necessary. What is impossible cannot exist, contingently or necessarily.

Taking all these into consideration, the objects or entities of pure mathematics are mathematical pure possibilities 6 . "Pure" means exemption from any spatiotemporal and causal conditions or restrictions as well as an independence of anything actual or physical. Thus, pure possibilities (in this case, mathematical pure possibilities) are necessary existents that do not exist anywhere, that are not temporal, and that do not play any causal role. For instance, numbers as mathematical pure possibilities do not exist in time and in place and they are not causes or effects ${ }^{7}$. In contrast, the actualities of these pure possibilities are physical entities or events, spatiotemporally existing, whose existence, as dependent on fortuitous circumstances, is contingent. Admitting the 


\section{Philosophy International Journal}

necessary existence of numbers and geometrical figures does not entail the existence of their physical actualities, an existence that inescapably depends also on contingent circumstances, which have no necessity about them. Mathematical entities or objects exist entirely independently of actual reality. Were no actual reality to exist, mathematical objects or entities would still, necessarily, exist. Our acquaintance with and knowledge of purely mathematical objects or entities need neither experience nor any empirical knowledge. In contrast, actualities can be known or become acquainted with only by means of experience. Actualities are empirical entities or events. They are physical beings.

Each actuality is of an individual pure possibility, pertaining only to this actuality and cannot be shared by other actualities. The reason for this is that the individual pure possibility of an actuality is the individual identity that distinguishes that actuality from any other actuality or, generally, any other possible being. No two pure possibilities can be identical. Allegedly "two" identical pure possibilities are one and the same pure possibility. In contrast, two actualities that appear to be identical are still two and not one because they exist at two different places at the same time or at the same place at different times. Nevertheless, such cannot be the case of pure possibilities, which do not spatiotemporally exist. Thus, what appears to be "two" identical or indiscernible pure possibilities are, in truth, one and the same pure possibility (thus the famous Leibnizian law of the identity of the indiscernibles is entirely valid for individual pure possibilities). Hence, each such possibility serves as the identity of an actuality, if this actuality exists in fact. If not, the pure possibility still exists, entirely independently of spatiotemporality, causality, or anything actual or physical. Such is precisely the case of mathematical pure possibilities, the objects, entities, or existents of pure mathematics.

The "ought" pertains to the realm of pure possibilities, whereas the actual "is" pertains to actual reality. Indeed, pure possibilities are not only existents, they are also norms and values, showing us what the case should or ought to be. Mathematical pure possibilities, closely related to logical pure possibilities, are not only existents; they are also norms and values of rational thinking, of intellectual orientation, concerning also the actual world. Even though actual reality is contingent, it contingently actualizes the necessity pertains to the realm of pure possibilities and contingently meet its norms and values. Logic and mathematics share some aesthetic values and norms with art.
It is not a new idea that logic and mathematics are strongly akin to beauty. The Pythagoreans were the first to relate mathematics to art (especially music) and aesthetics. An eminent modern mathematician, Godfrey Harold Hardy, coined the famous claim about mathematics:"Beauty is the first test: there is no permanent place in the world for ugly mathematics"8. This claim is compatible with the logical necessity about mathematics. This necessity takes an indispensable part in the beauty of mathematics, which is especially indicated by the elegance and economy of its proofs. The rationality that mathematical logic portrays has a clearly normative aspect. Mathematical beauty and necessity are also sound indications for the normative and axiological aspects of mathematical pure possibilities, which are exempt from the contingencies and ugliness that, according to Hardy, prevail in empirical reality. Irrationality, too, leaves its marks upon our life and reality.

Following Aristotle's Metaphysics $(987 \mathrm{~b} 28$ and 987b11), according to the Pythagorean, everything that exists is either a number or an "imitation" (mimesis) or "representation" of it. Besides pure numbers, there are imitated entities, states, or events of these numbers. Note that ancient mathematicians were quite capable of reducing geometrical figures entirely to numbers and numerical relations. Thus, it is a famous Pythagorean idea that numbers are the first principles (archai) of everything. The term "mimesis" is rather equivocal and it requires clarification. Plato's frequent use of this term, according to which all sensuous and mathematical entities as well are imitations of the Ideas of dialectics, does not clarify enough this time-honored term and, in fact, leaves it quite metaphorical. Physical and mathematical entities are not actors or performers who represent or imitate some acting and talking characters. Artistic performances, according to Plato, are imitations in the lowest grade of phenomenal reality of higher, intellectual (noumenal) realities. Such performances may be considered as a literal sense of the term "imitation." Nevertheless, to ascribe this term to entities or objects that are not actors or performers is, in fact, quite metaphorical.

My use of the term "actualization," according to which physical entities and events actualize individual pure possibilities, is meant to be exempt from any metaphorical aura. It is a precise, clear, and literal term that refers to the relations between actualities and their individual pure possibilities quite adequately. 


\section{Philosophy International Journal}

To be actual, an entity must be possible from the outset. Impossibilities do not exist. The possibility that is the fundamental condition for the existence of an entity is necessarily pure because, antecedently to any spatiotemporal and causal conditions and circumstances, the possibility of this entity has to exist. Otherwise, such an entity could have not existed at all and from the outset. Regardless and independently of spatiotemporal and causal conditions, the question of the possibility of anything to exist at all has to be settled first. Any actuality could exist at different times and at different places, under different causal circumstances, and still be the same actuality. For it is its individual pure possibility that fixes the identity of the entity in question and this identity is not restricted by spatiotemporal, causal, or circumstantial conditions. The identity is necessary, whereas these conditions are contingent.

The identity of each entity distinguishes it from any other entity. Each entity has its own identity; and the identity of any entity is its individual pure possibility, distinguishing it from anything else, actual or purely possible. "To distinguish from" or "to discern from" entails "to relate to." As each individual pure possibility is discerned from any other individual pure possibility, it necessarily relates to any other individual possibility. Because each individual pure possibility necessarily relates to all the others, from which it is different, there are necessary, general or universal, relations between all individual pure possibilities. On the grounds of these relations, we can refer to universal or general models, properties, and the like. Yet the grounds for all these general or universal relations are individual pure possibilities, which are fundamental existents. The existence of actualities primarily depends on the existence of their individual pure possibilities. To be purely possible from the outset is a primary necessary condition for the existence of an entity, possible or actual.

To interpret the abovementioned ideas by Oscar Wilde in the light of a realistic metaphysics about individual pure possibilities may contribute significantly to the topics of the current paper.

\section{Why Not Possible Worlds but Individual Pure Possibilities Instead?}

At least since the 1970s, philosophical modal analysis has become quite familiar to literary theoreticians. Many of them have endorsed the philosophical notion of possible worlds, which they have found quite fruitful for their projects ${ }^{9}$.
Indeed, the notion of possible worlds has become very popular among philosophers in various fields, and only few philosophers have voiced serious doubts about this notion and its uses ${ }^{10}$. It should be noted that there are many disagreements and debates about this notion and there is no general consent among philosophers about it. Possible-world semantics is one of the fields in which this notion has proven to be useful, and one can hardly conceive modal logic without it. Nevertheless, considering ontology and metaphysics, there should be some serious doubts about this main-streamed notion. Even though quite a few philosophers, while discussing possible worlds, have picked up examples from literature or literary fiction (following David Lewis 1978, the character of Sherlock Holmes has become very popular among them) ${ }^{11}$, the notion of possible worlds should be put to many more examinations and doubts also in the field of literary theory.

I, for one, find this notion quite problematic and doubtful and, hence, much prefer the notion of individual pure possibility to that of possible worlds ${ }^{12}$. I have several reasons for doing so.

If it is argued that modal logic cannot dispense with possible worlds as truth-makers, why should we not prefer individual pure possibilities instead? Instead of quantifying over possible worlds, why should we not prefer modal quantifiers of individual pure possibilities? Individual pure possibilities can adequately serve as truth-makers, for such possibilities and their relationality, namely the general or universal ways in which they relate to each other, are the truth-makers of the propositions about them. Individual pure possibilities are simpler and clearer entities than possible worlds, which are much more complicated entities that need many more assumptions ${ }^{13}$. Individual pure possibilities are thus preferable. Nevertheless, a challenger of such an idea may argue that the number of individual pure possibilities is so huge that the violence of the reasonable principle of Occam's razor is an inescapable consequence of relying upon them. However, this is not a sound argument, for the number of possible worlds can be no less huge than that of individual pure possibilities; in fact, it is much greater. According to the possible worlds tradition, any deviation from or change of actual reality for any individual entity requires reliance upon a possible world. This renders the number of possible worlds as much greater or infinite, than the number of actual particulars, for the counterpart of each such particular may be different in each possible world. Thus the number of the individual pure possibilities of all actual entities, which is precisely the number of these actualities, is smaller than that of the 


\section{Philosophy International Journal}

possible worlds concerning these actualities and their "counterparts". Hence, the idea of individual pure possibilities is much more parsimonious than that of possible worlds.

Moreover, the notion of possible worlds raises at least four apparently unsolvable epistemic problems, the first of which is well known. First, how can we have an epistemic access to any world that is different from our actual world and entirely separate from it? Such possible worlds take no part in our actual world and have no connections with it, causal, spatiotemporal, or otherwise. If, on the contrary, they are parts of our actual world, they are not world's at all but only non-actual parts of this world; as a result, there are no possible worlds but only one, actual world. And, alternatively, if the (purely) possible worlds and the actual one overlap, at least to some extent, the distinction between them must become a serious problem. Second, if a necessary truth is true in (or valid for) all possible worlds, how can we be familiar with all of the possible worlds in order to decide whether a truth is necessary? Third, if possible worlds are total, how can we conceive such totalities which are not formal or mathematical but replete with concrete entities down to their last detail? Are not such totalities beyond our cognitive capability? Fourth, we do not discover possible worlds, we only can stipulate them, but, if such is the case, how can we get any solid truth about them? Are not all such truths simply stipulated and subject to our arbitrary decisions or whims? What is the value or significance of such truths? In contrast, individual pure possibilities are discoverable by means of our intellect and imagination. We can discover what are the individual pure possibilities of entities, whether these entities are actual or merely possible. We can make such discoveries simply by considering entities regardless or independently of any spatiotemporal or causal conditions or restrictions. In this way, we can discover the individual pure possibility of any entity we encounter or even imagine.

Let me explain or demonstrate this by an example. Suppose that on an island, completely isolated and far from the main land, the inhabitants had never encountered bats, nor heard anything about them. Nevertheless, these people are educated, intelligent, and imaginative enough to surmise the pure ("mere") possibilities of flying mammals. Without stipulating any possible world, they form quite a few true propositions about these merely possible creatures, each of which is an individual pure possibility. Forming these propositions, they use their cognitive capability of transcending actual, empirical data ${ }^{14}$, simply by relying upon their intellect and imagination (which are not confined to empirical or actual data as well as to any spatiotemporal and causal restrictions). Such propositions are: (1) "(merely possible) flying mammals are not birds"; (2) "they are not reptiles"; (3) "they may feed on fruits growing on tall trees"; (4) "some of them may feed on flying insects"; (5) "they have wings suitable for flying fairly fast and high"; (6) "their offspring feed on the milk of female flying mammals"; (7) "like other mammals, they are also intelligent creatures", and many more true propositions like these. Most of these truths are necessary $(1,2,5,6$, and 7). None of these truths relies upon the notion of possible world. In our actual reality, we obviously encounter bats; and each bat has its sole individual pure possibility, distinguishing it from any other bat; otherwise, no such individual creature could exist at all.

\section{Theories as Fictions Discovering Pure Possibilities that are Mind-Independent}

The individual pure possibilities that are actualized and become actualities are mind-independent. Nevertheless, pure possibilities can be grasped by our intellect and imagination without relying upon empirical or physical reality. We can think about and imagine individual pure possibilities even if we never experience or hear of any actual indication of their existence. Pure mathematics refers in this way to mathematical pure possibilities. Our imagination and intellect are abundantly used to discover mind-independent pure possibilities that are indispensable for recognizing and identifying some actualities. Without grasping their pure possibilities first, we could not recognize and identify these actualities. For instance, a purely mathematical symmetry group served to predict and finally discover the actualities of subatomic particles, such as omega-minus. That group consists of mathematical pure possibilities, which had been discovered by means of a mathematical theory or fiction, whereas the relevant actualities were finally discovered, empirically, in the laboratory. There are many examples of theoretical discoveries (concerning pure possibilities) that predicted the existence of the relevant actualities and their actual, empirical discovery. The Higgs boson is a fine example, and there are many others. For instance, eka-elements in the periodic table of the chemical elements provide other fine examples of theoretical discoveries of purely possible elements that later happened to be discovered as actualities.

Fictions are created by us and, thus, they are minddependent, whereas, by means of fictions or theories, we can discover mind-independent possibilities, which actual reality may actualize and which exist quite independently of their discovery by us. Scientific theories, like art and 


\section{Philosophy International Journal}

mathematics, employ various fictions or conjectures to capture the individual pure possibilities without which we cannot know and understand nature and ourselves. All thought-experiments rest strongly upon such fictions in order to discover the mind-independent pure possibilities of the relevant actualities. For instance, the geocentric conjecture is a fiction of a thought-experiment that helped Copernicus ${ }^{15}$, and many other scientists after him, to discover the pure possibility of the actual fact that the earth travels around the sun and not vice versa. Empirical observations have confirmed this fact, and the theory, discovering its pure possibility by means of a fiction of a thought-experiment, adequately explains and clarifies it. Insights need first the discovery of the relevant pure possibilities, which are the identities of the entities that we attempt at understanding. Thus, understanding or insights rest upon our knowledge of individual pure possibilities as the identities of the relevant actualities. Art, no less than insightful scientific theories, uses fictions to discover mind-independent individual possibilities and their universal relations, in order to recognize, know, and understand ourselves and the reality around us as well.

It is an aim of thought-experiments to discover new pure possibilities that had not been considered as possible, and thus were denied or ignored. It is the possibility as pure that sets out the first challenge for a theoretical discovery. Not all discoveries are of actualities; there are no less important discoveries-theoretical ones, those of pure possibilities. Thought-experiments, relying not upon empirical knowledge but upon our imagination and intellect, are fruitful methods to discover and study new pure possibilities.

\section{Representation, Actualization and Evaluation}

Does art, especially literature, attempt to represent reality? Such is the view that has been shared by many, to begin with Plato. In this paper, I follow quite another way. Relying upon free imagination, art does not necessarily follow actual reality; rather the contrary-it captures individual pure possibilities that actual reality realizes and represents. Otherwise, what makes imagination free, if not its independence of anything actual? If not its capability of relating to and capturing pure possibilities? The objects of perception are actualities, whereas the objects of free imagination are individual pure possibilities and their general or universal relations. As for our intellect, our capability of making implications and inferences transcends beyond the empirical, perceptual, and actual. This is very typical of our intellect. What are the objects that transcend the limitations of actual reality? They are individual pure possibilities and their relations.

Thus, literature, at its best, may not represent reality but may relate to and capture the individual pure possibilities that empirical reality may actualize. Actualities partly represent ("imitate") pure possibilities under spatiotemporal and causal restrictions. These conditions or restrictions involve partial actualization, for actualities are the conditioned or restricted parts of their pure possibilities. Actual possibilities, namely, actualities, are thus the conditioned or restricted parts of their pure, more comprehensive, possibilities. Actualities are not the images of their pure possibilities. Images are minddependent pure possibilities by means of which we may relate or refer to actualities with which we are familiar.

The reason for which Wilde thought that nature imitates or represents art should be revised and completed in the light of the above concerning individual pure possibilities and their actualities. Strictly speaking, it is not art that nature represents or imitates but art is one of the best ways to discover and study the individual pure possibilities (including their universal or general relations) that nature and human lives actualize. Art reveals these possibilities and renders us insightful as regards their actualities. Art helps us greatly in identifying some meaningful actualities, especially about us. Without art, we would have been blind to these actualities, regarding their identity, meaning, and, especially, their values. Meaning and significance rest upon individual pure possibilities and their relations. The meaning and significance of actualities pertain to the individual pure possibilities of these actualities. And so are their values on which their evaluation relies. We evaluate actualities against their individual pure possibilities.

Each individual pure possibility is complete, whereas any actuality is only a partial actualization of its pure possibility, for this actuality could have existed under quite different circumstances and still remained this actuality and not another. As long as it is the actuality of that individual pure possibility, its identity is kept under whatsoever circumstances. Each individual pure possibility comprises all the possibilities (including circumstantial ones) that pertain to this possibility, which is an identity of an individual actuality. Grasping an individual pure possibility, we can realize also how could it exist, act, and relate and not only the actual possibilities that its actual existence, action, and relations have exhausted. 


\section{Philosophy International Journal}

On the grounds of individual pure possibilities and their actualities, we can clarify the Aristotelian-Wildean claims that genuine art reveals the "must," "ought," or "should" according to which actualities could be. Remember that any individual pure possibility is necessary. The modality of possibility, necessity, existence, and the ought are thus well integrated. As closer actualities are to their pure possibilities, as much as they actualize their pure possibilities, they are closer to their perfection or completeness. The contingency about actualities is minimal, whenever their actualization is closer to meet the completeness of their pure possibilities, to meet or answer their own standards. An individual pure possibility is, thus, the norm of its actuality.

\section{Realism about Individual Pure Possibilities is Incompatible with Idealism}

The modal metaphysical platform for my arguments in this paper is realistic about individual pure possibilities that are mind-independent and which we do not invent but discover. Thus, this platform is not compatible with any kind of idealism. In contrast, Vivian's view in Wilde's "The Decay of Lying" endorses a sort of idealism ${ }^{16}$. Only on the basis of such an idealism, is Vivian allowed to claim that Nature and Life imitate Art rather than vice versa. In contrast, my view argues that nature and life actualize the individual pure possibilities that art may reveal (the same holds true for science, but elaborating on this major issue is beyond the scope and aim of this paper). This actualization is considered as a sort of imitation, somewhat close to that which Wilde's Vivian has in mind (with one major reservation). Moreover, like Vivian's approach, my approach rejects the realistic-mimetic or representative view of art, according to which art represents or imitates our actual reality (as life and nature are concerned). Free imagination liberates the genuine artist from the bonds of actual-empirical reality as well as from any attempt to represent or imitate it. Yet, genuine art maintains an intimate, strong, and deep contact with our actual reality, for such an art reveals most meaningful individual pure possibilities that our actual reality has actualized.

Following Vivian, one has some grounds to consider nature and life as if "creations" of our mind as the originator of science, from one hand, and art, from another. For, according to Vivian, science and art are necessary for our seeing (to be distinguished from just lookingat) nature and life. Recognizing, identifying, and understanding what we see necessarily depends upon our mind as the originator of art and science. At this point, Wilde's Vivian is closer to a sort of Kantian idealism.
Nevertheless, the trouble with such a view, one to which Wilde's Vivian subscribes, is the one with any kind of idealism-Berkelean, Leibnizean, or Kantian transcendental idealism, namely, no idealism can explain how reality that is independent of our mind, that is without our mind, has to yield to the models, ideals, or patterns that either science or art create.

In contrast, the metaphysical modal platform upon which my discussion in this paper relies, does explain why independent reality, such as nature, has to yield to the individual pure possibilities and their relations that science or art reveals or discovers. Any actualization is of this or that individual pure possibility without which a particular actuality is not possible. Any actualization is of something that without this actualization still exists as an individual pure possibility, namely, as-yet a non-actual possibility. By means of our intellect and imagination, our mind can grasp such individual pure possibilities and their relations without relying upon experience, experiment, or observation concerning actual, empirical reality. The grasping of mind-independent individual pure possibilities is not achieved by means of perception or by any empirical means, which perceive the actual and does not grasp the purely possible ${ }^{17}$. Thus, our epistemic access to empirical, actual reality needs to be mediated by means of the access of our intellect and imagination to the individual pure possibilities that our life and nature actualize. Once we doubt the existence of an individual pure possibility, let alone exclude it, we cannot perceive or be aware of anything that could be considered as its actuality (even if this actuality does exist independently of our knowledge). Suppose that a scientist would exclude the very possibility of a particular sub-atomic particle. Had such a scientist encountered indications for the actual existence of such a particle, in experiments or observations performed in a modern collider, he could not identify them as indications for the existence of such an actuality but must misinterpret them or simply ignore them as meaningless or insignificance. Most of the time, we are not aware of the tacit acceptance in which we relate to the individual pure possibilities of the actualities that we observe and identify. However, whenever scientists exclude the individual pure possibility of, say, a particular virus, they would not have recognized its actuality while looking at its image through an electron microscope. They would not see, using Wilde's Vivian words, what they looking at.

Vivian assumes that what we see (to be distinguished from what we just look at) is because of its beauty, otherwise we would not pay any attention to it and simply ignore or overlook it. He thinks that things must have 


\section{Philosophy International Journal}

some value or significance in order to cause us to see them. In my terms, the meaning, significance, and value of any actuality stem from its individual pure possibility ${ }^{18}$. Without accepting or admitting this possibility, we would not pay any attention to the actuality in question and thus we would not see it. Nevertheless, this is quite different from Vivian's claim about this matter, for he refers to the beauty of things, whereas we in fact pay no less attention to ugly things that we cannot ignore ${ }^{19}$. Ugliness, like beauty and any other value, pertains to the individual pure possibility of an actuality. It pertains to the modal realm of values, significance, and meanings, which are embodied, namely, actualized, in empirical reality.

Just as there are pure possibilities that are mindindependent, so actual reality, actualizing some of these possibilities, is also mind-independent. Hence, idealism is groundless.

\section{An Example: Life Actualizes or Imitates Kafkaesque or Pinteresque Individual}

\section{Pure Possibilities}

In our life, we encounter scenes whose most appropriate adjectives are "Kafkaesque" (after Franz Kafka) or Pinteresque (after Harold Pinter). We may have a strong feeling that such scenes are performances, better, actualizations, of what is presented in scripts depicted by Kafka or Pinter. In this sense, these scripts appear as though staged in daily reality. The atmosphere of complete absurdity, distortion, meaningless existence, and stalemate, ambiguity, confusion, and puzzlement or that of dread and heavy discomfort, distress, embarrassment, perplexity, anxiety, or horror with which their writings are replete, such atmospheres are not representations of reality. These writings reveal the pure possibilities of such atmospheres and, moreover, of the Kafkaesque or Pinteresque characters, that we may recognize in the daily reality in which we live. This, amongst other artistic merits, is what makes Kafka's writings or those by Pinter so overwhelming, so powerful, and inescapable. We may find ourselves trapped in the pure possibilities that Kafka's fiction or that by Pinter relates to. Their fiction captures the purely possible scripts according to which some scenes of the reality in which we live are performed. Pinteresque pauses, the atmosphere of menace, absurd dread, suffocation, horror, and other Pinteresque traits can be detected as hidden in the most mundane conversations, phrased in an entirely colloquial language. In this way, Pinter hints at fear, dread, menace, and the like hidden among the common details of daily life, with which each of us is acquainted.
Kafkaesque situations emerge out of the most mundane bureaucratic reality or the political one.

Kafka wrote his masterpieces years before Hitler and Stalin appeared on the stage of history. Kafka was not a prophet. Yet, he revealed the very possibilities of such lives, in which terror, dread, mental suffocation, and inescapability prevail. His pure imagination captured the purely possible grounds on which lives under the regime of Hitler or Stalin had become actual.

Kafkaesque and Pinteresque pure possibilities, like other individual pure possibilities, are exempt from spatiotemporal and causal conditions or restrictions, and this exemption makes it possible for them to be actualized much longer after the creation of the fictions by Kafka or Pinter. Thus, such possibilities can be actualized even in our current era and all over the world. There are no geographical, political, social, and otherwise restrictions on them.

Yet, we have a problem to face. The problem is that within Kafka's fictions or those by Pinter, the pure possibilities of characters, events, actions, behavior, and manners of speaking, are obviously individual. There is always some particularity about them; literary scenes are never abstract. They are thus not general or universal. In what way, then, are these individual pure possibilities, whose realm of existence is the fiction either by Kafka or by Pinter, valid for actualities existing in our lives and reality?

The validity of these individual pure possibilities is general and universal. What actual reality has actualized have not been the individual pure possibilities that appear in the relevant fictions, but many other individual pure possibilities that could not have been recognized and discerned without those that the fictions by Kafka or Pinter have presented to us. For instance, the figure of Joseph K. in Kafka's The Trial, including his actions, thoughts, relations, and the like, all pertain to an individual pure possibility of a person, Joseph $\mathrm{K}$, who does not exist outside of Kafka's masterpiece. The same holds for the situation in which Joseph $\mathrm{K}$. becomes a suspect, even one convicted in advance, simply because of an anonymous informer. Nevertheless, the individual pure possibility in The Trial is necessarily relevant to or valid for a huge number of related individual pure possibilities of similar acts of informing and of similar victims in states under despotic regimes and sometimes even in some democratic or liberal states, in which a ruthless bureaucracy actualizes Kafkaesque possibilities to trap innocent victims. The pure possibilities existing in the 


\section{Philosophy International Journal}

fiction are individual, yet their relevancy or validity is universal or general. Each person or situation has an individual pure possibility that cannot be shared with other persons or with other situations. Yet, the individual pure possibilities of great art enlighten actual reality generally or universally in the way that I have just described.

Such is the case because, unlike the individual pure possibilities themselves, their general or universal relations are shareable by manifold individual pure possibilities, sharing common relevancy or validity as if they belong to the same family of individual pure possibilities. Such is the case of the individual pure possibilities in Kafka's fictions and of all Kafkaesque individual pure possibilities as well, which have been actualized in daily life. All these possibilities belong to the same family of pure possibilities and all take part in the same family resemblance. The same holds true for the individual pure possibilities in Pinter's writings and all the Pinteresque pure possibilities that have been actualized in daily life. Unlike the individual pure possibilities, their properties are general, and these properties rest upon the general relation and the general relevancy or validity of the involved individual pure possibilities. In this way, models are produced.

Kafkaesque or Pinteresque individual pure possibilities have been actualized in our daily life. Thus, these individual pure possibilities are mind-independent and they are distinct from the individual pure possibilities that Kafka's fictions or those by Pinter created and which thus depend on the mind of their author respectively. Kafkaesque or Pinteresque individual pure possibilities have been revealed for us thanks to the individual pure possibilities that were created in those fictions.

In this way, life actualizes simila ${ }^{20}$, Kafkaesque or Pinteresque, individual pure possibilities and, in this way, life imitates or represents them. Without the individual pure possibilities that Kafka's fictions and those by Pinter created, we could not recognize the Kafkaesque or Pinteresque ones that their writings revealed to us and that daily lives actualize. This recognition opens our eyes to identify and understand these lives and the reality in which they actually exist. Kafkaesque or Pinteresque possibilities thus endow us with indispensable insights about our lives and reality. Moreover, they provide us with major values by which we can profoundly evaluate these life and reality.

\section{Challenging Erich Auerbach's View Concerning the Representation of Reality in Western Literature}

Auerbach's Mimesis is a fine example of an approach that brilliantly subscribes to the view that Western literature, beginning with Homer's Odyssey and ending with Virginia Woolf's To the Lighthouse ${ }^{21}$, imitates or represents actual reality, most of all everyday, quite mundane, reality. In Auerbach's view, great masterpieces, such as Homer's Odyssey, Dante's Divine Comedy, Joyce's Ulysses, Proust's Remembrance of Things Past, and Virginia Woolf's To the Lighthouse represent or imitate reality, inner-mental or external-objective. In fact, my view in the current paper challenges Auerbach's approach, for as I see them, each of these masterpieces demonstrates that literature or myths reveal pure possibilities that reality, mental or external, actualizes.

Let me challenge, rather briefly, some examples that Auerbach analyzes. Chapter One, "Odysseus's Scar," in Mimesis is devoted to an analysis of a wonderful digression focusing on a boyhood reminiscence of Odysseus when as a young boy, he paid a visit to his grandfather Autolycus, during which the young Odysseus courageously hunted a mighty boar that wounded him and left a scar on his thigh. Washing the stranger's legs and noticing the scar, Euryclea, the old housekeeper and Odysseus's wet-nurse, immediately recognizes him as someone who has already seemed to her as resembling her lost master. He silences her, and the goddess Athene helps him to distract Penelope's attention in order to prevent her from recognizing him as her husband. These incidents took place before Odysseus overcame his wife's suitors with the same kind of weapon with which he had overcame the boar, together with the same courage and determination. This is the point at which I attempt to refute Auerbach's analysis of this scene. The reality in which Odysseus overcomes the suitors is a re-enacting or actualizing of the pure possibilities-the prospect and capability-that the remembered story of hunting the boar reveals. His victory over the suitors is an imitation and actualization of the boyhood reminiscence as revealing the mental capability of his courage and determination. This capability is a mental pure possibility.

Moreover, Odysseus's constant wish and determination is to return to his home and family. A Homeric legend that was not included in the Iliad narrates how Odysseus, who did not want to depart from his newborn son, Telemachus, nor his dear wife, pretended to become mad and so he ploughed the sea as if it were his 


\section{Philosophy International Journal}

field. One of the kings who came to draft him to the army preparing for the war on Troy, put the little Telemachus in the path of the plough, and Odysseus continued to plough but circumvented Telemachus in a semicircle. This was clear evidence of Odysseus's sanity; as a result, he was drafted and doomed to exile from his home and beloved family for a very long time. This legend throws a clear light on his constant behavior in the Odyssey as a whole, as actualizing the prospects (which are mental pure possibilities)of longing for and dearly loving his home and family. Odysseus turns his back on all heroic myths about kings and gods. He much prefers the mundane life at home with his beloved family and is ready to fight heroically to return to his wife and to overcome all the suitors. The myths about heroic kings and gods, in contrast, do not show him the values and the prospects (as pure possibilities) that he appreciates and chooses to actualize in his everyday life. In contrast, the story of his boyhood reminiscence reveals the pure possibility that he values and succeeds inactualizing, which ends in removing all the obstacles that have prevented him from his most desired home coming. This reminiscence enlightens us how to read the whole plot of the Odyssey with insight. The pure possibilities that this digression in the narration of the plot reveals are the source from which the reader can draw the right conclusions required for understanding and enjoying the Odyssey.

Turning to Dante's Divine Comedy, in Chapter Eight, Auerbach attempts to show how much the fantastic Divine Comedy is actually an imitation or representation of the mundane reality with which the author was very familiar. Auerbach reminds us of "Dante's assertion that in the Commedia he presented true reality" (Auerbach, Mimesis, p. 554) and he is amazed by "the astounding paradox of what is called Dante's realism" (op. cit.: 191). Nevertheless, I interpret this masterpiece in a different way-all the mundane details taken from Dante's everyday life and time or from the relevant history pertain to the actualization of the Inferno and the Paradise whose pure, non-actual possibilities this masterpiece reveals. In the midst of our everyday, actual life, we reveal the deepest meanings according to which this life is formed. In this way, we render as temporal the eternal or atemporal pure possibilities constituting the Inferno and the Paradise portrayed in the Divine Comedy. Our mundane and actual lives are thus actualities of the Divine Comedy on a human scale. Hence, the mundane, everyday, and human details in this masterpiece do not pertain to an imitation or representation of the actual reality in Dante's time. On the contrary, all these details are concrete actualities of specific pure possibilities that Dante's imagination revealed or discovered. As opposed to Auerbach's description-"We have left the earthly sphere behind; we are in an eternal place, and yet we encounter concrete appearance and concrete occurrence there. This differs from what appears and occurs on earth, yet is evidently connected with it in a necessary and strictly determined relation" (ibid.)-I think that the "eternal place" should be the realm of individual pure possibilities that are partly realized in the actualities that are concrete appearances and occurrences, and this should be the nature of the "necessary and strictly determined relation" between these possibilities and such actualities.

Auerbach reminds us of the detailed depiction, in fact an imitation, of everyday events, situations, and many details, some of which appear to be quite minor, not only in the Odyssey but even more in Marcel Proust's Remembrance of Things Past, James Joyce's Ulysses, and Virginia Woolf's To the Lighthouse. In my view, the contrary is the case-according to each of these masterpieces, it is not literature that imitates everyday reality, it is rather the everyday, domestic reality that actualizes pure possibilities that myths, legends, or literary masterpieces reveal.

Proust's Remembrance of Things Past is an excellent example of demonstrating this. The case appears to be, at least to Auerbach, that tasting the petite Madeleine, an apparently minor detail taken from everyday life, arouses a clear and vivid memory in Marcel's mind of past, actual reality (Marcel is both the narrator and the main character of this novel). This memory appears to be about actual details of his childhood vacations at Combray. Is this in fact a "recovery of lost [actual] realities in remembrance" (Auerbach, Mimesis, p. 541)? This focal scene in the whole great masterpiece should not mislead us. Literature or artistic writing becomes for Marcel a way of life, a destiny according to which artistic writing about life is much more valuable, significant, and important than simply mundane "real" life. For Marcel, the sublimity of life can be achieved only by means of the literary depiction of life. The scene depicting the petite Madeleine leads him to the most significant lost memory of a very special night for his whole life as well as to this revelation concerning the literary depiction of life. For what was the most exciting event in this miraculous evening, when Marcel's mother, thanks to the generous consent of his father, was able to spend the night with her miserable, lonely son? This night did not lead to a realization of an Oedipal dream of both son and mother but only to the reading (by her to him) of a charming Oedipal novelFrançois le Champi by George Sand ${ }^{22}$. Thus, reading and hearing an Oedipal piece of art lies at the heart of this 


\section{Philosophy International Journal}

childhood scene, and all the concrete details involved in it are actualities of individual pure possibilities that only literature can reveal.

Similarly, a tiny detail in Vermeer's The Sight of Delft causes the dying writer, Bergotte, one of the significant characters of this novel, to see again that artistic masterpiece, only because this tiny detail is much more important in Bergotte's eyes than his very life (Proust, vol. I, pp. 184-186). Marcel, his aunt (who used to give him the petite Madeleines), and Bergotte, each of them, in its own way, prefers tales about life or artistic depictions and portrayals of life to life itself. Bergotte and Proust himself were entirely ready to sacrifice mundane life for the sake of the joy of art. Like Marcel's aunt, Proust himself spent many years of his life in his bed. The aunt did so for she preferred to watch life from her window and to hear descriptions about all the activities taking part in the everyday life of the village of Combray; and Proust spent many years in the bed in his closed room just for the end of writing literature about his life. The non-actual, pure possibilities that literary art or fiction discovers were more important for him than his actual life. For Marcel, as much as for Proust himself, life without literary writing was not worth living. For them, literary writing was the revealer of the meaning and value of life.

Proust's literary writing is an excellent example of the fact that life may imitate or actualize literary possibilities. Thus, the village of Illiers, in which Proust stayed in the summer vacations of his childhood, is nowadays called Illiers-Combray; and Cabour, on the shore of Normandy, has been identified as Balbec in his novel. Thousands of admiring Proust-"pilgrims" visit these two "Proustian" sites each year, experiencing them through the prism of Proust's novel. Again, it is not literature that must imitate or represent life; life may imitate or represent literature, at least in the mind of those who experience it in this way.

According to Auerbach, both James Joyce and Virginia Woolf were the prominent modern writers who, in their literary works, imitated the reality of daily life and of streams of consciousness. Indeed, reading Joyce's Ulysses may convince many readers that the imitation and representation of everyday life, entirely mundane life, is what Joyce has achieved: Leopold Bloom's preparing breakfast, reading a newspaper in the toilet(with many sensual details concerning this scene ${ }^{23}$ ), Molly Bloom's detailed interior monologue (extremely colloquial) and stream of consciousness (op. cit.: 871-933), all concrete details in Bloom's day, and, finally, his return to his wife's bed-all these are strictly mundane. Nevertheless, all these details are actualities of literary pure, non-actual possibilities taken ironically, even distortedly, from Homer's Odyssey, for Bloom's day is an Odyssey in Dublin, and Ulysses is the Latin name of Odysseus. Unlike Penelope, Molly Bloom is not faithful to her husband, and her stream of consciousness focuses on some carnal characteristics of her lover's body and sexuality, and yet she is a modern Penelope in her own way, choosing again her Leopold to be his wife, answering whole-heartedly "Yes" (the final word of Ulysses, op. cit.: 933) to his wish to be her husband. The irony, the humor, and the down-toearth reality pertain to actualities of Odysseyan literary possibilities. Literature, literary various styles and-above all-words are the core of Ulysses rather than the imitation of everyday reality. Like Dante, according to Auerbach's brilliant analysis of the Divine Comedy, Joyce succeeds in combining the everyday and mundane with the artistic sublimity of his writing. Molly's interior monologue is one of the most beautiful pieces of literary art. It is not an imitation of actual psychical life, for no one has access to the psychical, inner reality of another person. Such access can be achieved only in fiction, by no means in everyday life. In any case, literature does not necessarily imitate life; it is life that may imitate or actualize pure possibilities that only great literature can discover or reveal.

Similarly, such is the case of To the Lighthouse by Virginia Woolf. In the opening chapter of this novel, we are informed that little James Ramsay "belonged, even at the age of six, to the great clan which... must let future prospects ... cloud what is actually at hand" (Woolf, To the Lighthouse, p. 5). As future prospects are, in fact, pure possibilities (contrary to "what is actually at hand"), for this great clan such possibilities outweigh actualities. This certainly catches the spirit of To the Lighthouse as a whole.

Only a really great literary masterpiece such as this can demonstrate how horrible was the impact of the socalled "Great War" (the First World War) on a life of a family and its acquaintances. A frustrated childhood prospect (which was a pure possibility) to make a oneday journey to the nearby lighthouse and its actualization after the war, without making any sense or value, depicts the great disaster. All the everyday details, beginning with the brown stocking in Mrs. Ramsey's hands, lost their meanings while remaining in the deserted house, of which no meaning was left after the "Great War." Full of furniture and everyday belongings but empty of inhabitants, the house lost all the meanings it once had.

Analyzing To the Lighthouse, Auerbach rightly mentions "Lily Briscoe's concluding vision which enables 
her to finish her painting with one stroke of the brush" (Auerbach 2003: 552). Yet, this is an artistic scene in which artistic possibilities are actualized because of a vision. Is this vision an everyday event? Is there not something in it transcending actual, everyday events? In To the Lighthouse, too, artistic life gains the upper hand over everyday life, and Lily Briscoe's artistic achievement is an actualization of a vision-of a pure possibility or prospect-not of copying or representing what her eyes see in actual reality. It is art that reveals to the reader the meaning of the lives of the novel's characters and of the reader as well, and this great art is not a representation or imitation of reality. Rather, it serves as a vision for the reader, too. It reveals valuable and meaningful pure possibilities that life may actualize.

\section{Notes}

${ }^{1}$ Oscar Wilde, Oscar, The Decay of Lying. In The Complete Writings of Oscar Wilde, Vol. 7 (New York: The Nottingham Society, 1909), p. 41. For a reading of the Wilde trials transcripts as "a text reflecting and enacting Wilde's vision what literature is," see Marco Wan, "A Matter of Style: On Reading the Oscar Wilde Trails as Literature," Oxford Journal of Legal Studies 31 (2011), p. 710. It is a fascinating demonstration of how Wilde's life actualized, represented, or imitated his aesthetic ideas and values instead of the other way round.

${ }^{2}$ For a profound elaboration on such a realistic approach concerning literary masterpieces since Homer to Marcel Proust and Virginia Woolf, consider Erich Auerbach, Mimesis: The Representation of Reality in Western Literature. Trans. Willard R. Trask (Princeton: Princeton University Press, 2003).

${ }^{3}$ Vivian is quite consistent through the dialogue in interchanging "representation" with "imitation." See, for instance, Wilde, "The Decay of Lying," p. 43.

${ }^{4}$ Aristotle, Poetics. Translated by S. H. Butcher (New York: Dover, 1951), Poetics 1451a37-1451b11, pp: 35.

5 I introduced and elaborated on my metaphysics, named panenmentalism, in the following books: Amihud Gilead, Saving Possibilities: An Essay in Philosophical Psychology (Amsterdam\& Atlanta: Rodopi - Value Inquiry Book Series, Vol. 80, 1999);Singularity and Other Possibilities: Panenmentalist Novelties(Amsterdam \& New York: Rodopi - Value Inquiry Book Series, Vol. 139, 2003); Necessity and Truthful Fictions: Panenmentalist Observations(Amsterdam \& New York: Rodopi Value Inquiry Book Series, Vol. 202, 2009); and The Privacy of the Psychical(Amsterdam \& New York: Rodopi - ValueInquiry Book Series, Vol. 233, 2011).. Panenmentalism is a modal metaphysics that is realistic about individual pure possibilities. Nevertheless, it does not rely upon any conception of possible worlds. I have devoted several papers to the implications of this metaphysics
Hence, what Auerbach calls the entrance of the realism of daily life into the sublime and tragic (Auerbach, Mimesis, p. 22) ${ }^{24}$. I would prefer to consider as the unity of individual pure possibilities with their concrete actualities (which are the spatiotemporally and causally restricted parts of these possibilities, as I have explained above). These actualities thus imitate-better, actualize-the pure possibilities that literary masterpieces reveal for the reader.

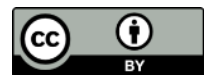

concerning some major issues in the philosophy of science. See the following papers: "Shechtman's Three Question Marks: Possibility, Impossibility, and Quasicrystals," Foundations of Chemistry 15 (2013): 209-224; "Pure Possibilities and Some Striking Scientific Discoveries,"Foundations of Chemistry 16 (2014): 149-163; "Chain Reactions, 'Impossible' Reactions, and Panenmentalist Possibilities," Foundations of Chemistry 16 (2014): 201-214; "Can Brain Imaging Breach Our Mental Privacy?" The Review of Philosophy and Psychology 6 (2015): 275-291; "Neoteny and the Playground of Pure Possibilities," International Journal of Humanities and Social Sciences 5 (2015): 30-39; "Eka-Elements as Chemical Pure Possibilities," Foundations of Chemistry 28 (2016):183-194; and "The Philosophical Significance of Alan Mackay's Theoretical Discovery of Quasicrystals," Structural Chemistry 28 (2017): 249-256.

${ }^{6}$ Henceforth, whenever I mention "pure possibility/ies," mathematical or otherwise, I intend to "individual pure possibility/ies," the reason for which will be discussed soon below.

${ }^{7}$ Contrary to the prevalent manner in which philosophers of mathematics consider purely mathematical entities as abstract, I systematically refrain from this term. In my view, abstract entities depend upon actual reality, as they are abstracted from it, whereas individual pure possibilities, mathematical or otherwise, are entirely independent of actual or empirical reality. Second, abstract entities are general, whereas individual pure possibilities are specific. Purely mathematical entities are specific, whereas the relations between them are general or universal. Mathematical models rely upon these general or universal relations and not on the mathematical entities themselves.

${ }^{8}$ A Mathematician Apology (Cambridge: Cambridge University Press, 1973). Hardy is known as a devoted supporter of pure mathematics, boasting that his work could never be used for practical purposes. See David Mumford, "Foreword: The Synergy of Pure and Applied Mathematics, of the Abstract and the Concrete." In: Mircea Pitici (ed.), The Best Writings in Mathematics 2012 (Princeton, NJ: Princeton University Press, 2013), p. x.It is quite interesting to compare this approach by Hardy to Vivian's idea that "art never expresses anything but itself" (Wilde, "The Decay of Lying," p. 42). 
${ }^{9}$ See, for example, Thomas G. Pavel, "Possible Worlds in Literary Semantics," The Journal of Aesthetics and Art Criticism 34 (1975/76): 165-176;Umberto Eco, The Role of the Reader: Explorations in the Semiotic of Texts(Bloomington, Ind.: Indiana University Press, 1979);DoreenMaître,Literature and Possible Worlds (London: Middlesex PolytechnicPress, 1983);Brian McHale, Postmodernist Fictions (London and New York: Routledge, 1987); Uri Margolin, "Individuals in Narrative Worlds: An Ontological Perspectives," Poetics Today 11(1990): 843-871;Marie-Laure Ryan, Possible Worlds, Artificial Intelligence and Narrative Theory, (Bloominton, Indiana: Indiana University Press, 1991);Ryan, "Possible Worlds in Recent Literary Theory," Style(1992) 26: 528-553; Ryan, "The Text as World vs the Text as Game: Possible Worlds Semanticsand Postmodern Theory," Journal of Literary Semantics 27 (1998): 137163; Ruth Ronen, Possible Worlds in Literary Theory (Cambridge: Cambridge University Press, 1994); Lubomír Doležel, "Possible Worlds and Literary Fictions," in Allén, Sture (ed.) Possible Worlds in Humanities, Arts and Sciences: Proceedings of Nobel Symposium 65 (Berlin and New York: Gruyter, 1989): 221-242; Doležel, Heterocosmica: Fiction and Possible Worlds (Baltimore: Johns Hopkins University Press, 1998); Doležel, Possible Worlds of Fictions and History: The Postmodern Stage(Baltimore: Johns Hopkins University Press, 2010); Thomas L. Martin, Poiesis and Possible Worlds: A Study in Modality and Literary Theory(Toronto: Toronto University Press, 2004);Daniel Punday, "Creative Accounting: Role Playing Games, Possible-World Theory, andthe Agency of Imagination," Poetics Today 26 (2005): 113-139;Elizabeth Klaver, "Possible Worlds, Mathematics, and John Mightons's 'PossibleWorlds'," Narrative(2006)14: 45-63; Davide Messina, "Qfwfq as Kafka? Possible-Worlds Interpretations," Modern Language Review 106 (2011): 1001-1027; Daniel Candel Bormann, "Moving Possible World Theory from Logic to Value," Poetics Today34 (2013): 177-231; and Robert Vogt, "Combining PossibleWords Theory and Cognitive Theory." In Nünning, Vera (ed.), Unreliable Narration and Trustworthiness: Intermedial and Interdisciplinary Perspectives (Berlin: De Gruyter, 2015): 131-153.0f course, some of these approaches are quite different from one another, yet they all, following a philosophical mainstream, endorse the notion of possible worlds.

${ }^{10}$ See, for instance, E. J. Lowe, "Metaphysics as the Science of Essence," presented at the conference The Metaphysics of E. J. Lowe(2006)

(http://ontology.buffalo.edu/06/Lowe/Lowe.pdf);Jonathan D. Jacobs, "A Power Theory of Modality: Or, How I Learned to Stop Worrying and Reject Possible Worlds," Philosophical Studies 151 (2010): 227-248;Barbara Vetter, "Recent Work: Modality without Possible Worlds," Analysis 71 (2011): 742-754; Kit Fine, "Counterfactuals Without Possible Worlds," The Journal of Philosophy109 (2012): 221-246; and Elijah Millgram, Chapter 7, "Lewis's Epicycles, Possible Worlds, and the Mysteries of Modality." In The Great Endarkenment: Philosophy for an Age of Hyperspecialization (Oxford: Oxford University Press, 2015): 155187.

${ }^{11}$ See David Lewis, "Truth in Fiction," American Philosophical Quarterly" (1978) 15: 37-46.

${ }^{12}$ Considering the motivation for possible-world literary or fictional semantics, Doležel writes: "Fictional particulars are necessary and indispensable constituents of literary fictions. Literature deals with concrete fictional persons... A model frame which does not accommodate the concept of fictional particular cannot be an adequate theoretical base of fictional semantics. . This serious deficiency of the one-world model leads us to explore the potentials of a radically different theoretical foundation of fictional semantics, the model frame of multiple, possible worlds" (Doležel, Possible Worlds in Humanities, pp. 228-29). Precisely for this purpose, we do not need possible worlds; we need, much more, individual pure possibilities without which no literary or fictional particular can exist!

${ }^{13} \mathrm{Or}$ are possible worlds not so complicated and demanding? Even an ardent follower of possible-world semantics, such as Lubomír Doležel, citing some philosophers, acknowledged: "Possible worlds of logical semantics are 'total' or 'maximally comprehensive' state of affairs, "maximal cohesive sum(s) of possibilia" (Doležel, Possible Worlds of Fictions, p. 31). And, citing Adams, each possible world is "a complete world history" (ibid.). Who is the human being that is capable of comprehending such totalities? Is there a literary fiction that portrayals a maximally comprehensive state of affairs or a complete world history? The solutions that have been suggested for these problems, some of which Doležel mentioned (e.g., mini possible worlds), raise more problems than answers. Like Doležel, I too, criticize (or reject) mimetic literary theory (see Doležel, PossibleWorlds in Humanities, p. x; cf. Ryan,"Possible Worlds in Recent Literary Theory,"p. 531), especially Auerbach's, but on quite different grounds. According to Doležel, authors make fictional possible worlds, whereas I think that authors create fictions that may discover mind-independent individual pure possibilities that actual reality may "imitate" (namely, actualize).

${ }^{14}$ Note that this kind of transcendence, contrary to the case of the "transcendence" of possible worlds, does not entail any separation from the actual, for no actuality is separable from its individual pure possibility. As I will explain below, any actuality is a spatiotemporally and causally restricted part of its individual pure possibility. Similarly, actual reality is a spatiotemporal and causal conditioned and restricted part of the whole realm that consists of all the individual pure possibilities.

${ }^{15}$ This famous example is taken from Immanuel Kant, Kritik der reinen Vernunft B (1787), p. xxii.

${ }^{16}$ As Vivian clearly puts it: "Consider the matter from a scientific or a metaphysical point of view, and you will find that I am right. For what is Nature? ... She is our creation. It is in our brain [mind] that she quickens to life. Things are because we see them, and what we see, and how we see it, depend on the Arts that have influenced us. To look at a thing is very different from seeing a thing. One does not see anything until one sees its beauty. Then, and then only, does it come into existence. At present, people see fogs, not because there are fogs, but because poets and painters have taught them the mysterious loveliness of such effects. There may have been fogs for centuries in London. ... But no one saw them, and so we do not know anything about them. They did not exist till Art had invented them" (Wilde, “The Decay of Lying," p. 39).

${ }^{17}$ Note again that abstractions are drawn from actual reality, and, thus, they necessarily depend on it, whereas individual pure possibilities are not abstractions, as these possibilities are entirely independent of actual reality. Hence, the empirical means (such as perception) in which we perceive actualities cannot serve us in grasping or conceiving individual pure possibilities.

${ }^{18}$ This entails a realism about meanings or that meanings can be mind-independent. Of course, not all meanings are mindindependent. There are also mind-dependent meanings, which are subjective or intersubjective. The combination "mind-independent meanings" is not common, yet it was accepted by Frege, Gödel, and 
other realists about meanings (for instance, structuralists). For Frege's use of it, see Barry Smith, "Frege and Chomsky: Sense and Psychologism," in: John Biro and Petr Kotatko (eds.) Frege: Sense and Reference One Hundred Years Later (Dordrecht: Kluwer, 1995), pp. 31-32. For Gödel's use of it, consult Richard Tieszen, "Mathematical Realism and Gödel's Incompleteness Theorems," Philosophia Mathematica 2 (1994): 177-201.

${ }^{19}$ Interestingly enough, the word "ugly" is mentioned only once in The Decay of Lying, while realism is discussed. Vivian says about realism that it "inevitably makes people ugly" (Wilde, "The Decay of Lying, p. 31).

${ }^{20}$ Remember that no two individual pure possibilities can be identical, and thus even similar individual pure possibilities are different from each other.

${ }^{21}$ Virginia Woolf, To the Lighthouse (Harmondsworth, Eng.: Penguin Books, 1964 [1927]).

22 “...this book which my mother had read aloud to me at Combray until the early hours of the morning had kept for me all the charm of that night" (Marcel Proust, Remembrance of Things Past. Trans. by C. K. Scott Moncrieff, Terence Kilmartin, and Andreas Mayor (London: Chatto and Windus, 1981), vol. I, pp. 44-46cf. vol. III, pp. 919-920). All this excellently fits Marcel's idea that art is "the most real of all things" (op. cit., vol. III, p. 914) or "Real life, life at last laid bare and illuminated-the only life in consequence which can be said to be really lived-is literature. ... art, if it means awareness of our own life, means also awareness of the lives of other people-for style for the writer ... is a question not of technique but of vision; it is the revelation ..." (op. cit., vol. III, p. 931).

${ }^{23}$ James Joyce, Ulysses (London: Penguin Books 1992 [1922]), pp. 83-84.

${ }^{24} \mathrm{Cf} .:$ "any aesthetic separation of the realms of the sublime and tragic on the one hand and of the everyday and real on the other is of course out of the question" (Auerbach, Mimesis, p. 92); "It situates the sublime event within their everyday lives" (op. cit.: 156); "there is no basis for a separation of the sublime from the low and everyday" (op. cit.: 158); "a complete embedding of the sublime and sacred event in a reality which is simultaneously contemporary Italian and omnitemporal" (op.cit.: 172); "Many important criticsand indeed whole epochs of classicistic taste-have felt ill at ease with Dante's closeness to the actual in the realm of the sublime is monstrous" (op. cit.: 185); "Shakespeare's mixing of styles in the portrayal of his characters is very pronounced. In most of the plays which have a generally tragic tenor there is an extremely close interweaving of the tragic and the comic, the sublime and the low" (op. cit.: 315). 